\title{
Beneath the Retinal Pigment Epithelium: Histopathologic Findings in Metastatic Extranodal Natural Killer/T-Cell Lymphoma, Nasal Type
}

\author{
Atalie C. Thompson ${ }^{\mathrm{a}}$ Chad M. McCall ${ }^{\mathrm{b}}$ Alan D. Proia ${ }^{\mathrm{b}}$ \\ a Department of Ophthalmology, Duke University Medical Center, Durham, NC, USA; ${ }^{b}$ Department of Pathology, \\ Duke University Medical Center, Durham, NC, USA
}

\section{Established Facts}

- Extranodal natural killer/T-cell lymphoma (ENKTCL), nasal type rarely involves the orbital/ocular adnexal tissue.

- ENKTCL has a high mortality rate, and orbital/ocular adnexal involvement portends an even worse prognosis.

- ENKTCL is not only positive for Epstein-Barr encoding region in situ hybridization, but is also CD56 positive, which helps to distinguish it from Epstein-Barr virus-positive anaplastic large cell lymphoma.

\section{Novel Insights}

- ENKTCL metastases were located between the retinal pigment epithelium (RPE) and the Bruch membrane and spared the uveal tissue, distinguishing it from metastatic B-cell lymphoma that tends to involve the choroid.

- The presence of autoantibodies to glyceraldehyde 3-phosphate dehydrogenase and loss of the RPE and photoreceptors in areas without lymphoma support paraneoplastic lymphoma-associated retinopathy as a cause of the patient's complete loss of vision in both eyes.

\section{Keywords}

Extranodal natural killer/T-cell lymphoma, nasal type · Intraocular lymphoma · Metastases · Sub-retinal pigment epithelium lymphoma - Lymphoma-associated retinopathy

\footnotetext{
Abstract

Purpose: To report a case of extranodal natural killer/T-cell lymphoma (ENKTCL), nasal type metastatic to the space beneath the retinal pigment epithelium (RPE) with coincident paraneoplastic lymphoma-associated retinopathy. Methods: Findings of clinical and histopathologic examination
}

are presented with differential diagnoses and a literature review. Case Report: A 53-year-old man presented with bilateral blindness and had exudative retinal detachments overlying subretinal masses in both eyes. Flow cytometry of pericardial fluid revealed malignant $\mathrm{T}$ lymphocytes. After two cycles of chemotherapy, the patient was hospitalized and quickly expired. Autopsy revealed lymphoma involving the eyes, heart, right lung, and two subcarinal lymph nodes focally. Histopathologic examination of the eyes revealed intraocular metastases from ENKTCL, nasal type. Expression of CD3 and CD56, along with expression of Epstein-Barr virus by in situ hybridization, confirmed the diagnosis. Lympho-

\section{KARGER}

(c) 2018 S. Karger AG, Basel

E-Mail karger@karger.com

www.karger.com/oop
Alan D. Proia, MD, PhD

Department of Pathology - DUMC 3712

Duke University Medical Center

Durham, NC 27710 (USA)

E Mail alan.proia@ duke.edu 
matous infiltrates were confined to the space beneath the neurosensory retina and between the RPE and the Bruch membrane, sparing the uveal tissue, similar to other metastatic T-cell lymphomas. Extensive RPE and photoreceptor loss in regions with and without underlying tumor was typical of a concurrent paraneoplastic lymphoma-associated retinopathy. Conclusion: Patients diagnosed with ENKTCL should be evaluated by an ophthalmologist, as ophthalmic involvement portends a poor prognosis.

(c) 2018 S. Karger AG, Basel

\section{Introduction}

Extranodal natural killer/T-cell lymphoma (ENKTCL), nasal type is a rare but aggressive malignant neoplasm that typically arises in the paranasal sinuses or nasal cavity [1], but has also been documented in the skin and soft tissue, upper respiratory and gastrointestinal tracts, and testes [2]. Like other non-Hodgkin lymphomas, it can masquerade as an intraocular inflammatory or infectious process [3], which can lead to delayed diagnosis and vision loss. The prognosis for ENKTCL is substantially worse than that of other T-cell or B-cell lymphomas [4], especially if patients present late or if there is orbital or ocular adnexal involvement $[2,5]$. Early diagnosis is thus of utmost importance, but can prove quite challenging. Previous studies have documented orbital/ocular adnexal involvement of ENKTCL, both as a primary [5-10] and secondary [4, 10-13] manifestation of the disease. Intraocular involvement is quite rare with only a small number of published cases $[4,14-$ 16]. To our knowledge, we are the first to report a case of ENKTCL metastatic to the space beneath the retinal pigment epithelium (RPE). The case is also remarkable for a coincident paraneoplastic lymphoma-associated retinopathy associated with anti-retinal autoantibodies to glyceraldehyde 3-phosphate dehydrogenase (GAPDH).

\section{Case Report}

A 53-year-old African American man experienced gradual onset of photopsia and floaters in both eyes during the preceding year. Four months prior to presentation, he noticed a dramatic, painless decline in his vision over several weeks. An outside ophthalmologist documented his visual acuity at 20/400 on the right and hand motion on the left, while his intraocular pressure was 17 $\mathrm{mm} \mathrm{Hg}$ in both eyes. His external examination and extraocular movements were normal. Fine inferior keratic precipitates and rare cells were seen in the anterior chamber and vitreous, along with $2+$ nuclear sclerotic cataracts in both eyes. Dilated fundus examination revealed bilateral multifocal chorioretinal pigmentary changes with macular serous pigment epithelial detachments and inferior exudative retinal detachments.

Systemic workup for infectious and inflammatory etiologies of possible panuveitis with chorioretinitis at an outside hospital was negative for Bartonella spp., Lyme disease, cytomegalovirus, Epstein-Barr virus (EBV), toxoplasmosis, Tropheryma whipplei, human immunodeficiency virus, tuberculosis, and sarcoidosis. He was hypotensive and short of breath, and an echocardiogram revealed cardiac tamponade requiring pericardiocentesis. Flow cytometry of the pericardial fluid demonstrated a population of lymphocytes strongly positive for $\mathrm{CD} 3, \mathrm{CD} 56$, and $\mathrm{CD} 7$ markers, but with weak expression of $\mathrm{CD} 2$, loss of $\mathrm{CD}$, and no expression of CD4, CD8, or T-cell receptors alpha/beta and gamma/delta. A computed tomography scan of the head did not reveal any intracranial, nasal, or paranasal sinus lesions. A positron emission tomography/computed tomography scan showed nonspecific fluorodeoxyglucose activity in the hilar and mediastinal lymph nodes. Our patient was treated for peripheral T-cell lymphoma with EPOCH (etoposide, prednisolone, Oncovin [vincristine], cyclophosphamide, hydroxydaunorubicin).

After two cycles of chemotherapy, the patient developed altered mental status, hypotension, and fevers. Blood and cerebral spinal fluid cultures showed no growth, and cerebral spinal fluid tests for venereal disease research laboratory, cryptococcal antigen, herpes simplex virus antibody, and cytology were negative. $\mathrm{He}$ was started on empiric broad-spectrum antimicrobial coverage and transferred to Duke University Hospital's intensive care unit. Ophthalmology evaluation in the intensive care unit found that he was unable to perceive light in either eye. Large, bilateral, multifocal, subretinal infiltrates and masses with overlying serous retinal detachments and mild vitreous opacities were noted in the posterior pole and midperiphery. Arteriolar narrowing and patches of atrophic RPE in regions of attached retina were also present. The optic nerves appeared normal, and magnetic resonance imaging of the brain and orbits without contrast confirmed symmetric optic nerves of normal signal intensity without evidence of orbital, nasal, paranasal sinus, or intracranial involvement. The patient quickly became hemodynamically unstable and expired upon transitioning to comfort measures. Autopsy revealed disseminated lymphoma involving the heart, right lung, and two subcarinal lymph nodes focally. Lymphoma was absent in paraaortic and paratracheal lymph nodes. The nasal cavity and paranasal sinuses were not examined due to the potential for disfigurement.

Horizontal sectioning of the right eye revealed a flocculent white mass beneath the RPE (Fig. 1a) and a large circular region of hypopigmentation with patchy stippled melanin pigmentation of the neurosensory retina just nasal to the optic disc (Fig. 1b). The RPE overlying the white tumor was stippled (Fig. 1c). Regions of atrophic neurosensory retina also existed in regions where subretinal tumor was notably absent (Fig. 1d). There was no gross evidence of tumor invasion of the choroid, ciliary body, iris, or optic nerve. Similar findings were present in the left eye.

Microscopic examination revealed multifocal lymphoma with extensive tumor necrosis localized beneath the neurosensory retina and RPE of both eyes (Fig. 2a). Tumor cells were mostly medium-sized or larger pleomorphic cells with prominent nucleoli (Fig. 2b). Larger cells were often multinucleated. Extensive, patchy loss of RPE cells was associated with degeneration of the overlying photoreceptors and outer nuclear layer. RPE and photoreceptor/ outer nuclear layer degeneration existed not only in areas with un- 


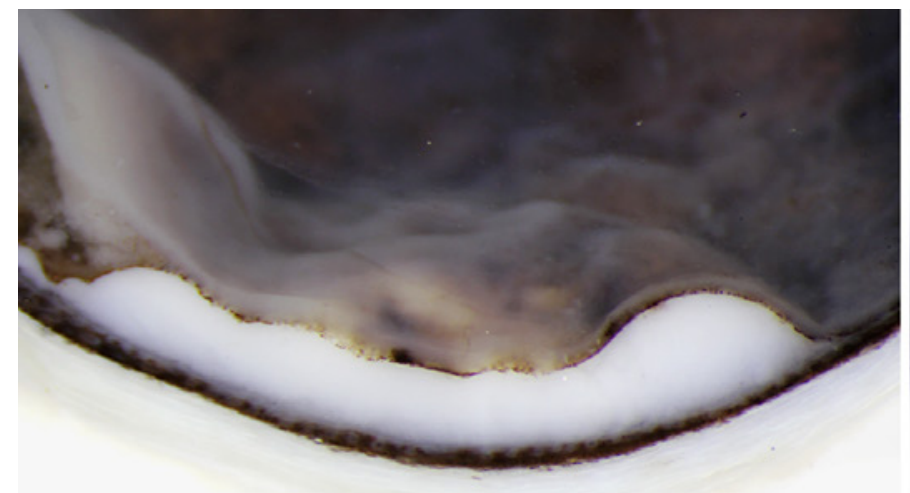

a

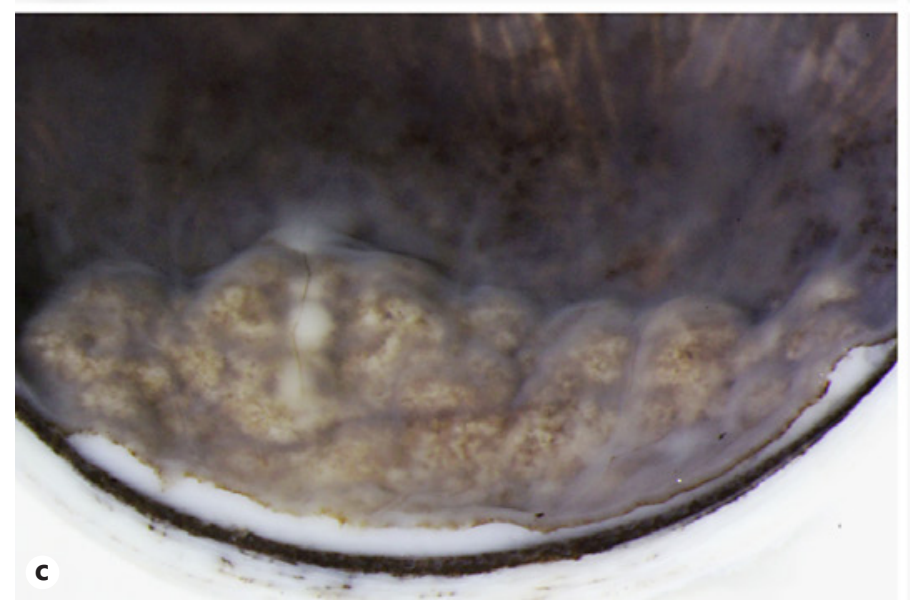

Fig. 1. a, b The right eye had a flocculent white mass beneath the RPE (a) and a large circular region of hypopigmentation with patchy stippled melanin pigmentation of the neurosensory retina just nasal to the optic disc (b).c The RPE overlying the white tumor was stippled. d Regions of atrophic neurosensory retina also ex-

derlying sub-RPE lymphoma (Fig. 2c), but also in regions that lacked lymphomatous infiltrates (Fig. 2d). Tumor cells had the following immunophenotype, with the estimated percentage of cells staining positively in parentheses: CD3 (>99\%; Fig. 3a), granzyme B (>99\%; Fig. 3b), TIA-1 (>99\%; Fig. 3c), CD30 (90\%), CD56 (8090\%; Fig. 3d), CD7 (90-95\%; Fig. 3e), CD20 (30-40\%), MUM1 (5\%), CD5 (<5\%), CD8 $(<5 \%)$, and CD2 $(<5 \%)$. Lymphoma cells did not express CD4, PAX-5, CD79a, CD138, anaplastic lymphoma kinase 1, or human herpes virus 8. Epstein-Barr encoding region in situ hybridization was also positive in all nonnecrotic tumor cells (Fig. 3f). The diagnosis was ENKTCL, nasal type in both eyes. Bilateral loss of RPE/photoreceptors in areas devoid of lymphoma was interpreted as lymphoma-associated retinopathy, and subsequent Western blot analysis of postmortem blood (Ocular Immunology Laboratory, Casey Eye Institute, Oregon Health and Science University, Portland, OR, USA) revealed anti-retinal autoantibodies against the $36-\mathrm{kD}$ GAPDH protein, but no marked immunohistochemical staining of human retina.

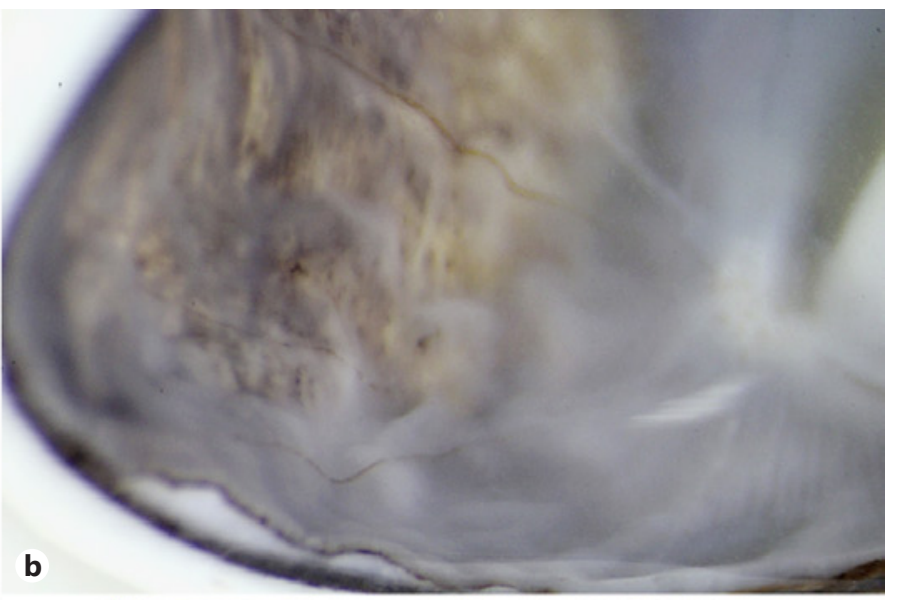

d

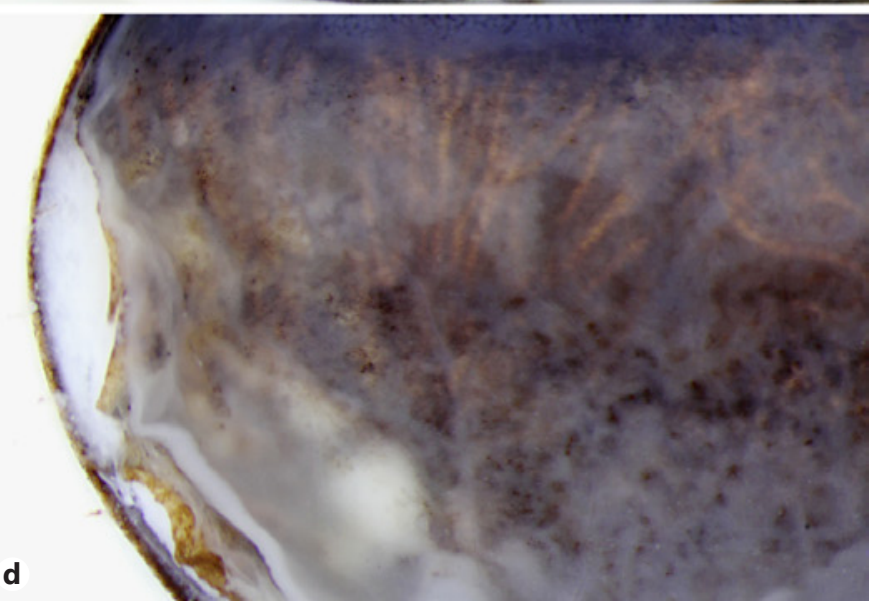

isted in regions where subretinal tumor was absent; the atrophic retina appears clearer than the normal translucent white retina, which results from formalin fixation. RPE, retinal pigment epithelium.

\section{Discussion}

According to the 2017 World Health Organization classification system, natural killer/T-cell lymphoma, nasal type is a rare, extranodal lymphoma derived from cytotoxic $\mathrm{T}$ cells or natural killer cells [1]. It commonly presents in adult men, especially in Asia and Central America, but there are infrequent reports of cases in Europe and the USA [17]. Seventy to ninety percent of ENKTCLs originate in the nasopharynx, although disseminated and extranasal disease also occurs $[2,3,12,18]$, as it did in our patient. This malignancy is characterized by an aggressive angiodestructive growth pattern and tumor necrosis [18] as well as a pathogenic link to EBV [19-22]. In our patient, the histologic appearance of the lymphomatous infiltrates 

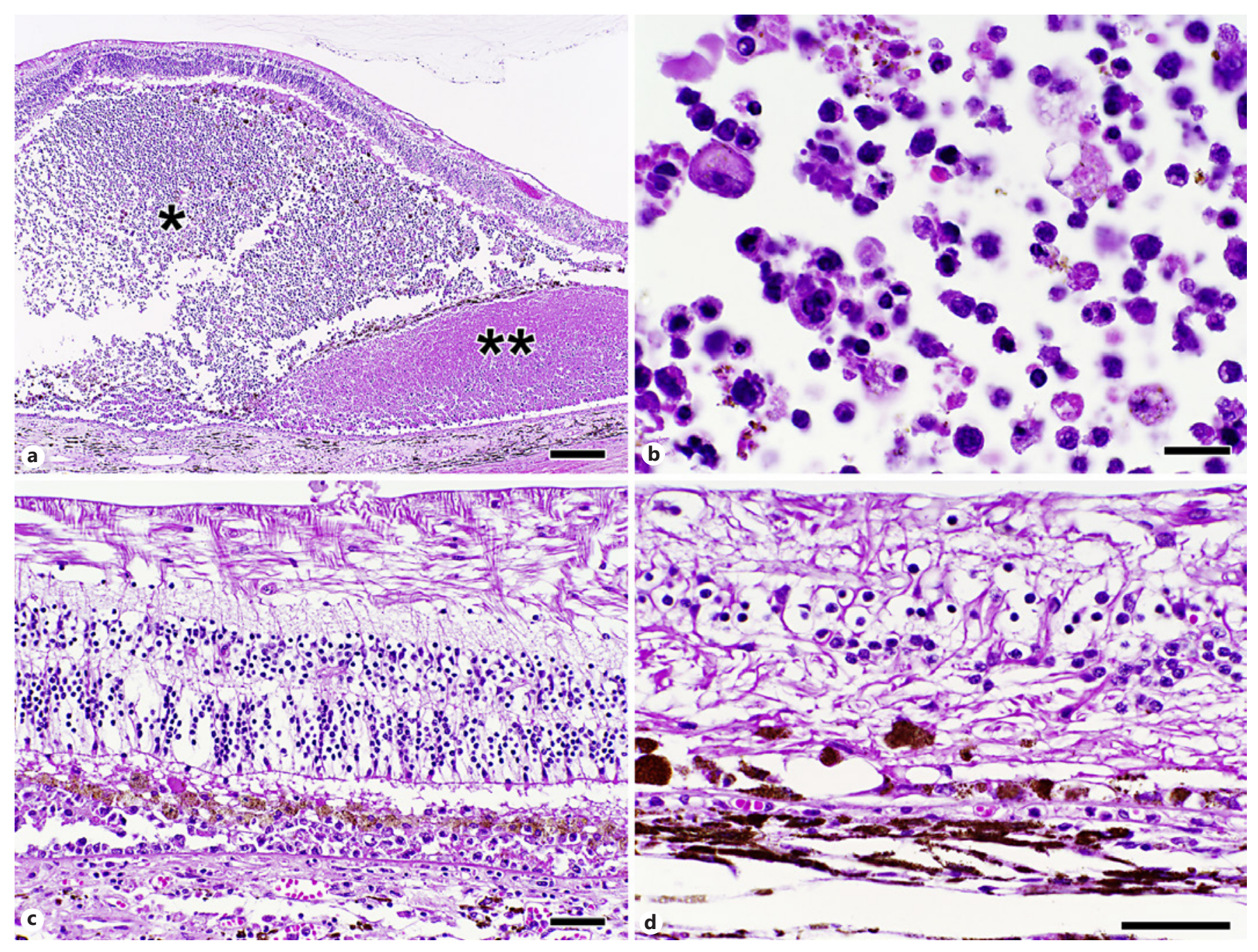

Fig. 2. a Lymphoma with extensive tumor necrosis was localized beneath the neurosensory retina $\left(^{*}\right)$ and the RPE $\left({ }^{* *}\right)$ of both eyes. $\mathrm{H} \& \mathrm{E}$. Scale bar, $250 \mu \mathrm{m}$. b Tumor cells were mostly medium-sized or larger pleomorphic cells with prominent nucleoli. H\&E. Scale bar, $20 \mu \mathrm{m}$. c, d RPE and photoreceptor/outer nuclear layer degen-

eration existed not only in areas with underlying sub-RPE lymphoma (c), but also in regions that lacked lymphomatous infiltrates (d). H\&E. Scale bars, $50 \mu \mathrm{m}$. RPE, retinal pigment epithelium.

and the expression of EBV by in situ hybridization helped us to confirm the diagnosis of ENKTCL, nasal type [18]. In addition, the lymphoma cells uniformly expressed the T-cell marker CD3 and the cytotoxic granule-associated proteins granzyme B and TIA-1, and a majority of the cells were positive for CD7 and CD30. Approximately 80-90\% of the cells expressed CD56, which helped to distinguish this case from EBV-positive anaplastic large-cell lymphoma, which should have only a subset of lymphoma cells weakly expressing CD56 [23]. Flow cytometry analysis of tumor cells in pericardial fluid lacked expression of T-cell receptors alpha/beta and gamma/delta, ruling out the pos-

sibility of a gamma-delta T-cell lymphoma such as has been described recently as a presenting cause of vison loss [24]. In addition, gamma-delta T-cell lymphomas are typically negative for EBV-encoded RNA [25].

Our patient was unusual in that the metastases to the eyes were intraocular and did not originate in the nasal cavity or paranasal sinuses. In general, metastases to the eye and ocular adnexa from T-cell lymphomas are uncommon compared to B-cell lymphomas [11, 26-28]. Orbital/ocular adnexal involvement in the nasal type of ENKTCL is usually secondary to invasion from the adjacent nasopharynx $[4,10-13]$. In the largest available

Sub-RPE Metastases from Extranodal

Ocul Oncol Pathol 2018;4:388-394 

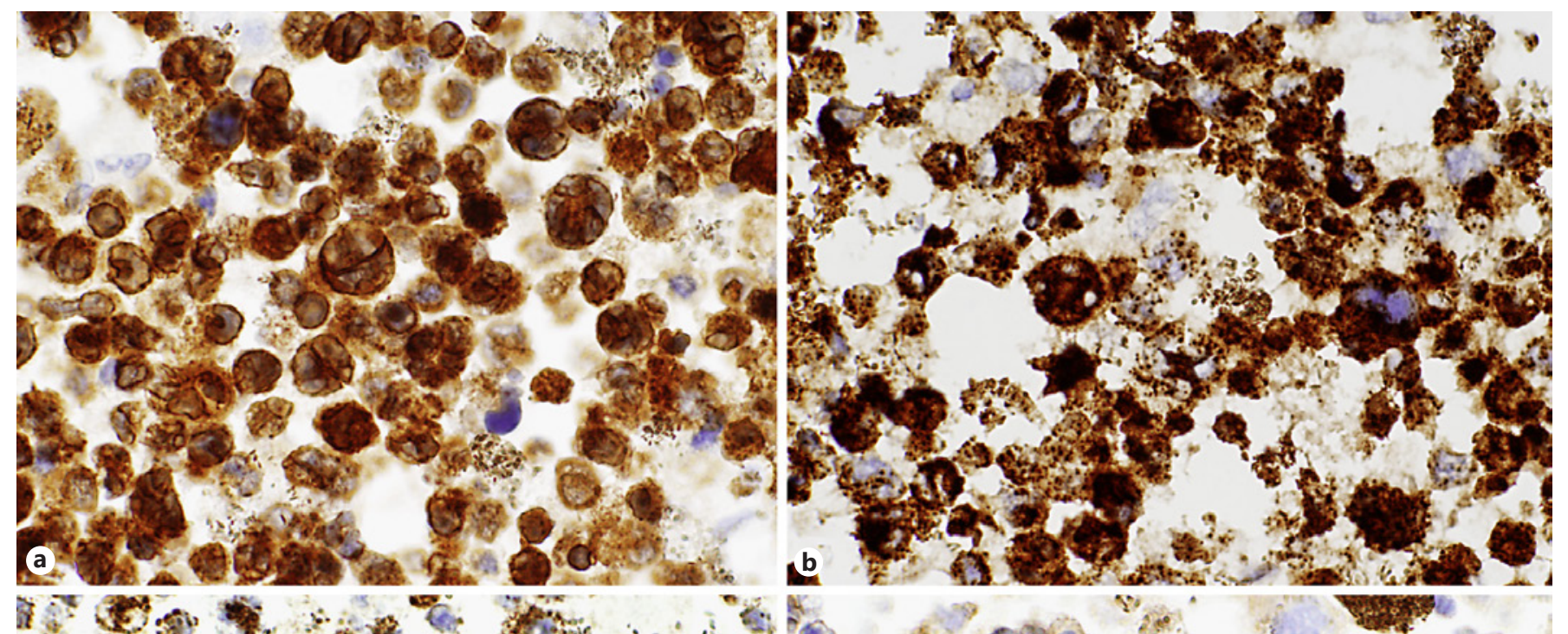

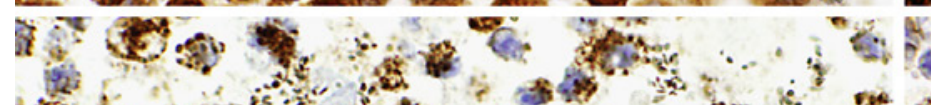

$60 x^{2}+x^{2}$

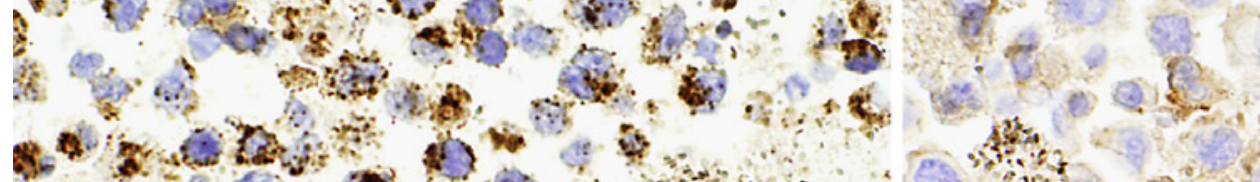

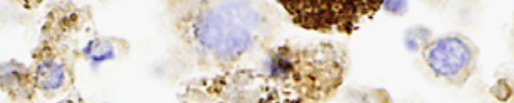

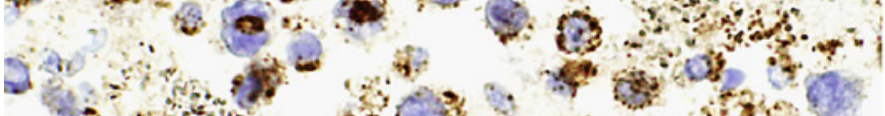

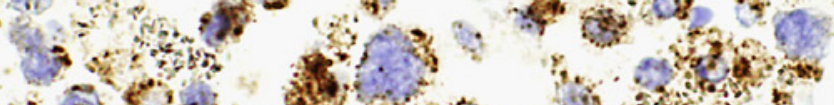

4.

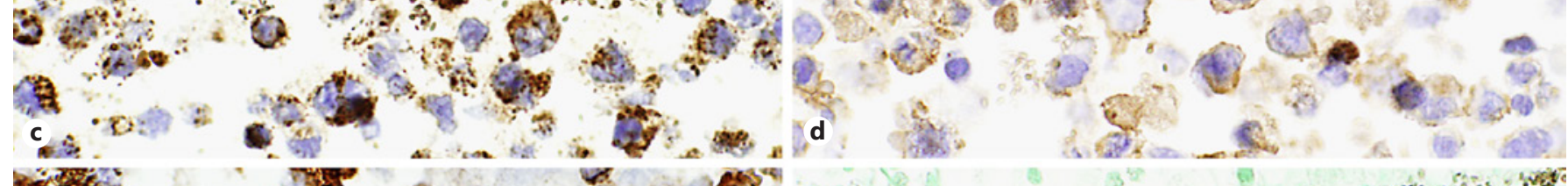

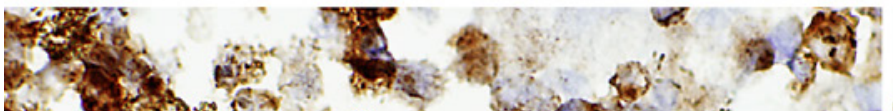

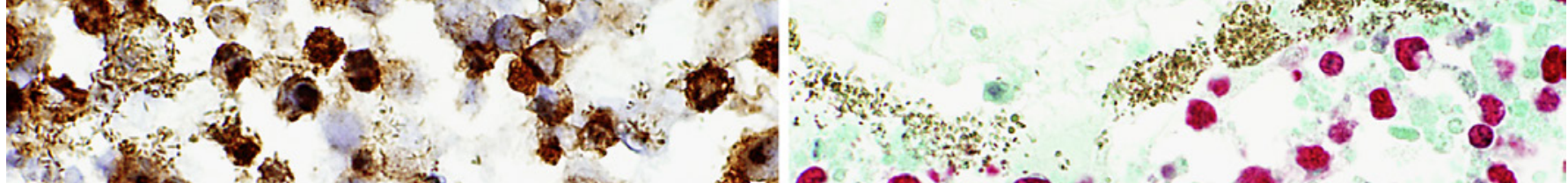

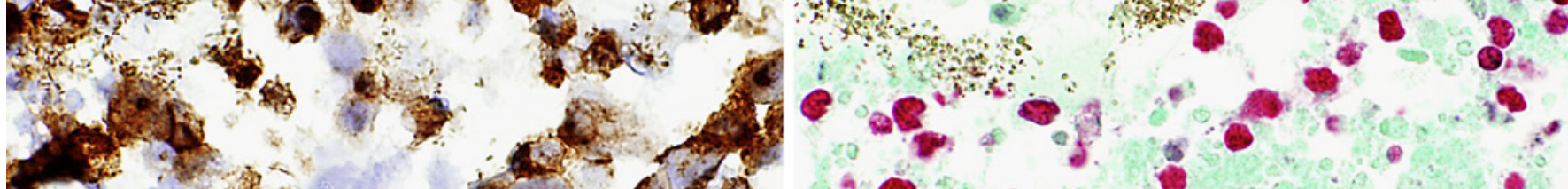

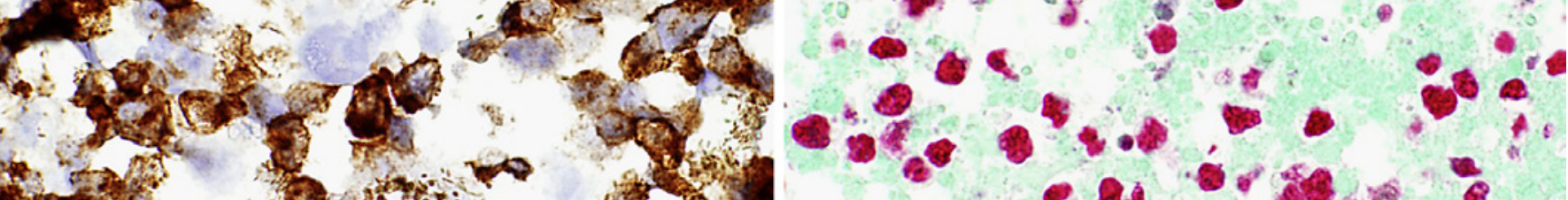

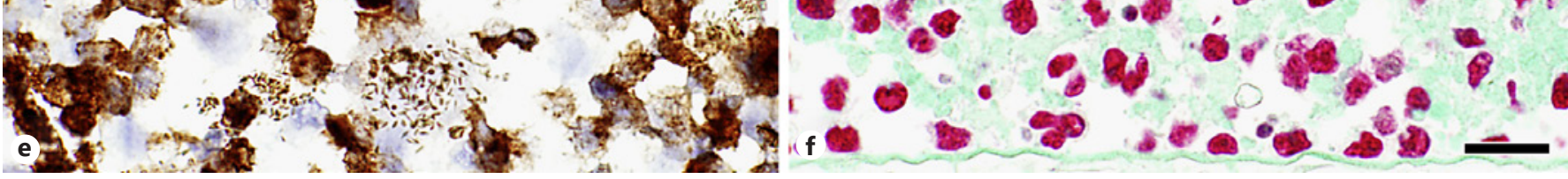

Fig. 3. a-e Immunohistochemical staining showed expression of CD3 (a), granzyme B (b), TIA-1 (c), CD56 (d), and CD7 (e). f Epstein-Barr encoding region in situ hybridization was positive in all nonnecrotic tumor cells. Scale bar for a-f, $20 \mu \mathrm{m}$. 
retrospective review of patients with ENKTCL, nasal type, 9.6\% of 115 subjects had secondary ocular invasion, though it was not specified whether the invasion was orbital, intraocular, or both [13]. Orbital/ocular adnexal involvement of ENKTCL in the absence of nasal/sinus disease is extremely uncommon, with only 13 reported cases in the literature [5-10].

Intraocular ENKTCL has also been reported rarely [4, 14-16]. In a series of 24 cases with nasal and paranasal sinus ENKTCL, 6 patients experienced vision-threatening ocular complications ranging from uveitis and vitritis to orbital involvement [12]. In one published case of nasal ENKTCL, vitritis improved following intrathecal chemotherapy and intravitreal methotrexate; however, there were no uveoretinal lesions noted on the dilated fundus examination [15]. Another patient with intraocular ENKTCL was treated with methylprednisolone for presumed optic neuritis due to optic nerve edema; autopsy subsequently revealed posterior optic nerve invasion by the tumor [3]. Cimino et al. [4] reported a patient with nasal type ENKTCL who developed vitritis and retinochoroidal lesions. Diagnostic vitrectomy confirmed the diagnosis of intraocular spread of the lymphoma, but the histopathology of the retina and choroid was not examined.

To our knowledge, we are the first to document the histopathologic findings of ENKTCL metastatic to the subretinal space. In our patient, the lymphoma masqueraded clinically as panuveitis with chorioretinitis. Unlike B-cell lymphomas, which tend to metastasize to the uvea by hematogenous spread $[27,29]$, our patient did not have any lymphomatous infiltrate within the choroid, iris, or ciliary body. Rather, the natural killer/T-cell lymphoma metastases were confined to the space beneath the neurosensory retina and between the RPE and the Bruch membrane. This finding is similar to those of other types of T-cell lymphoma, which have a predilection for invasion of the vitreous and retina, sparing the choroid [27].

We are also the first to report an association of ENKTCL with anti-retinal autoantibodies to GAPDH along with histopathologic findings supporting lymphoma-associated retinopathy. Our patient's examination findings of attenuated vessels with patchy RPE changes, as well as extensive loss of RPE cells and photoreceptors on histopathology, are typical of cancer-associated retinopathy/lymphoma-associated retinopathy [30-32]. GAPDH plays a central role in photoreceptor cell glycolysis and is the second most common antigenic target in autoimmune retinal diseases $[33,34]$. Although cancerassociated retinopathy has been widely documented in patients with solid tumors of the breast, lung, and gyne-

Sub-RPE Metastases from Extranodal

NK/T-Cell Lymphoma, Nasal Type cologic system [35], reports of hematologic malignancies are quite rare $[36,37]$. In one case of lymphoma-associated retinopathy, serum antibodies against a $47-\mathrm{kD}$ retinal protein were detected in a patient with follicular cell lymphoma [36], while antibodies to a $65-\mathrm{kD}$ retinal protein were reported in Hodgkin lymphoma [37]. Given the clinical course and histopathologic findings in our patient, we believe that his rapid and complete vision loss was multifactorial, resulting not only from retinal degeneration overlying the sub-neurosensory retina and the sub-RPE lymphoma, but also from a lymphoma-related paraneoplastic retinopathy that obliterated the RPE and photoreceptors throughout the remaining, otherwise attached, peripheral retina. Our case should however be interpreted with a caveat. Since there was no marked immunohistochemical staining of retinal tissue using postmortem blood, the anti-GAPDH autoantibodies might not have been pathogenic to the retina and may have been nonspecifically present in the serum.

The prognosis of ENKTCL is poor, with a 5-year cumulative survival ranging from 37.9 to $45.5 \%$ and a median survival approximated at 12.5 months $[2,10,12,18]$. While early stages may respond to radiation therapy, most patients present late and will fail multimodal treatment with chemotherapy and adjuvant radiation $[2,5,7$, $8,10,13]$. Orbital/ocular adnexal involvement may portend an even worse outcome. In one review of 9 cases of primary orbital ENKTCL, the median survival was a mere 4 months [5]. Our patient had widespread systemic and intraocular disease at the time of initial presentation, and he declined within 3 months despite aggressive chemotherapy and intensive care management. Patients with ENKTCL should be referred to an ophthalmologist to evaluate for intraocular and periocular involvement, including any evidence of lymphoma-associated retinopathy, as such findings may portend a poor prognosis.

\section{Statement of Ethics}

This submission complies with the guidelines for human studies. Approval of the Duke Health Institutional Review Board was not required. Consent to publish this case report was not obtained as the authors' only involvement with the patient was performance of the autopsy and review of the clinical records. This report does not contain sufficient personal information for identification of the patient.

\section{Disclosure Statement}

The authors have no conflicts of interest to disclose. 


\section{References}

1 Chan JKC, Quintanilla-Martinez L, Ferry JA: Extranodal NK/T-cell lymphoma, nasal type; in Swerdlow SH, Campo E, Harris NL, Jaffe ES, Pileri SA, Stein H, Thiele J (eds): WHO Classification of Tumours of Haematopoietic and Lymphoid Tissues. Lyon, International Agency for Research on Cancer, 2017, pp 368-371.

- 2 Al-Hakeem DA, Fedele S, Carlos R, Porter S: Extranodal NK/T-cell lymphoma, nasal type. Oral Oncol 2007;43:4-14.

-3 Abe RY, Pinto RD, Bonfitto JF, Lira RP, Arieta CE: Ocular masquerade syndrome associated with extranodal nasal natural killer/T-cell lymphoma: case report. Arq Bras Oftalmol 2012;75:430-432.

4 Cimino L, Chan CC, Shen D, Masini L, Ilariucci F, Masetti M, Asioli S, Sartori A, Cappuccini L: Ocular involvement in nasal natural killer T-cell lymphoma. Int Ophthalmol 2009; 29:275-279.

5 Ely A, Evans J, Sundstrom JM, Malysz J, Specht CS, Wilkinson M: Orbital involvement in extranodal natural killer T cell lymphoma: an atypical case presentation and review of the literature. Orbit 2012;31:267-269.

-6 Kanzaki A, Funasaka Y, Nakamizo M, Shima A, Ryotokuji T, Dan K, Terasaki M, Sugisaki Y, Fukuda Y, Kawana S, Saeki H: Extranodal natural killer/T-cell lymphoma, nasal type, with primary manifestation as an upper eyelid swelling. J Nippon Med Sch 2016;83:177-179.

-7 Kiratli H, Uzun S, Yesilirmak A, Ayhan AS, Soylemezoglu F: Conjunctival extranodal natural killer/T-cell lymphoma, nasal type. Cornea 2015;34:710-712.

8 Marchino T, Ibanez N, Prieto S, Novelli S, Szafranska J, Mozos A, Graell X, Buil JA: An aggressive primary orbital natural killer/T-cell lymphoma case: poor response to chemotherapy. Ophthalmic Plast Reconstr Surg 2014; 30:e131-e134.

-9 Meel R, Dhiman R, Wadhwani M, Kashyap S, Sharma S, Gogia A: Isolated extranodal natural killer T-cell lymphoma of the orbit in a young patient: complete regression with the SMILE regimen. Ocul Oncol Pathol 2017;3: $45-48$.

10 Woog JJ, Kim YD, Yeatts RP, Kim S, Esmaeli B, Kikkawa D, Lee HB, Korn BS, Punja K, Habermann TM, Colgan JP, Salomao D, Cameron JD: Natural killer/T-cell lymphoma with ocular and adnexal involvement. Ophthalmology 2006;113:140-147.

11 Coupland SE, Foss HD, Assaf C, Auw-Haedrich C, Anastassiou G, Anagnostopoulos I, Hummel M, Karesh JW, Lee WR, Stein H: Tcell and T/natural killer-cell lymphomas involving ocular and ocular adnexal tissues: a clinicopathologic, immunohistochemical, and molecular study of seven cases. Ophthalmology 1999;106:2109-2120.
12 Hon C, Kwok AK, Shek TW, Chim JC, Au WY: Vision-threatening complications of nasal T/NK lymphoma. Am J Ophthalmol 2002; 134:406-410.

13 Wu X, Li P, Zhao J, Yang X, Wang F, Yang Y, Fang F, Xu Y, Zhang H, Wang W: A clinical study of 115 patients with extranodal natural killer/T-cell lymphoma, nasal type. Clin Oncol (R Coll Radiol) 2008;20:619-625.

14 Jaffe ES, Chan JK, Su IJ, Frizzera G, Mori S, Feller AC, Ho FC: Report of the Workshop on Nasal and Related Extranodal Angiocentric T/Natural Killer Cell Lymphomas. Definitions, differential diagnosis, and epidemiology. Am J Surg Pathol 1996;20:103-111.

-15 Lee EJ, Kim TW, Heo JW, Yu HG, Chung H: Natural killer/T-cell lymphoma of nasal type with intraocular involvement: case report. Eur J Ophthalmol 2010;20:215-217.

16 Yoo JH, Kim SY, Jung KB, Lee JJ, Lee SJ: Intraocular involvement of a nasal natural killer T-cell lymphoma: a case report. Korean J Ophthalmol 2012;26:54-57.

17 Macon WR, Williams ME, Greer JP, Hammer RD, Glick AD, Collins RD, Cousar JB: Natural killer-like T-cell lymphomas: aggressive lymphomas of T-large granular lymphocytes. Blood 1996;87:1474-1483.

18 Li S, Feng X, Li T, Zhang S, Zuo Z, Lin P, Konoplev S, Bueso-Ramos CE, Vega F, Medeiros LJ, Yin CC: Extranodal NK/T-cell lymphoma, nasal type: a report of 73 cases at MD Anderson Cancer Center. Am J Surg Pathol 2013;37: 14-23.

19 Harabuchi Y, Imai S, Wakashima J, Hirao M, Kataura A, Osato T, Kon S: Nasal T-cell lymphoma causally associated with Epstein-Barr virus: clinicopathologic, phenotypic, and genotypic studies. Cancer 1996;77:2137-2149.

20 Harabuchi Y, Yamanaka N, Kataura A, Imai S, Kinoshita T, Mizuno F, Osato T: EpsteinBarr virus in nasal T-cell lymphomas in patients with lethal midline granuloma. Lancet 1990;335:128-130.

21 Kanavaros P, Lescs MC, Briere J, Divine M, Galateau F, Joab I, Bosq J, Farcet JP, Reyes F, Gaulard P: Nasal T-cell lymphoma: a clinicopathologic entity associated with peculiar phenotype and with Epstein-Barr virus. Blood 1993;81:2688-2695.

22 Medeiros LJ, Jaffe ES, Chen YY, Weiss LM: Localization of Epstein-Barr viral genomes in angiocentric immunoproliferative lesions. Am J Surg Pathol 1992;16:439-447.

23 Ma L, Katz Y, Sharan KP, Schwarting R, Kim AS: Epstein-Barr virus positive anaplastic large cell lymphoma: myth or reality? Int J Clin Exp Pathol 2011;4:100-110.
24 Jones N, Gibb A, Irion L, Coupland S: Gamma-delta T-cell lymphoma of skin, eye and brain presenting with visual loss. BMJ Case Rep 2017;2017:bcr-2017-219946.

25 Foppoli M, Ferreri AJ: Gamma-delta T-cell lymphomas. Eur J Haematol 2015;94:206218.

26 Jensen OA, Johansen S, Kiss K: Intraocular Tcell lymphoma mimicking a ring melanoma. First manifestation of systemic disease. Report of a case and survey of the literature. Graefes Arch Clin Exp Ophthalmol 1994;232: 148-152.

27 Levy-Clarke GA, Greenman D, Sieving PC, Byrnes G, Shen D, Nussenblatt R, Chan CC: Ophthalmic manifestations, cytology, immunohistochemistry, and molecular analysis of intraocular metastatic T-cell lymphoma: report of a case and review of the literature. Surv Ophthalmol 2008;53:285-295.

28 Saga T, Ohno S, Matsuda H, Ogasawara M, Kikuchi K: Ocular involvement by a peripheral T-cell lymphoma. Arch Ophthalmol 1984;102:399-402.

29 Ozcan AA, Paydas S, Soylu M, Yavuz S: Bilateral choroidal infiltration from indolent nonHodgkin's lymphoma: a rapid course with poor prognosis. Leuk Lymphoma 2005;46: 615-617.

30 Goldstein SM, Syed NA, Milam AH, Maguire AM, Lawton TJ, Nichols CW: Cancer-associated retinopathy. Arch Ophthalmol 1999;117: 1641-1645.

- 31 Khan N, Huang JJ, Foster CS: Cancer associated retinopathy (CAR): an autoimmune-mediated paraneoplastic syndrome. Semin Ophthalmol 2006;21:135-141.

32 Shildkrot Y, Sobrin L, Gragoudas ES: Cancerassociated retinopathy: update on pathogenesis and therapy. Semin Ophthalmol 2011;26: 321-328.

33 Adamus G: Impact of autoantibodies against glycolytic enzymes on pathogenicity of autoimmune retinopathy and other autoimmune disorders. Front Immunol 2017;8:505.

34 Adamus G, Choi D, Raghunath A, Schiffman J: Significance of anti-retinal autoantibodies in cancer-associated retinopathy with gynecological cancers. J Clin Exp Ophthalmol 2013;4:307.

35 Adamus G: Autoantibody targets and their cancer relationship in the pathogenicity of paraneoplastic retinopathy. Autoimmun Rev 2009;8:410-414.

36 Bhavsar KV, Hedges T, Thirkill CE, Reichel E: Paraneoplastic retinopathy associated with systemic follicular cell lymphoma. Ophthalmic Surg Lasers Imaging Retina 2015;46:373376.

- 37 To KW, Thirkill CE, Jakobiec FA, Lessell S, Berson EL: Lymphoma-associated retinopathy. Ophthalmology 2002;109:2149-2153. 